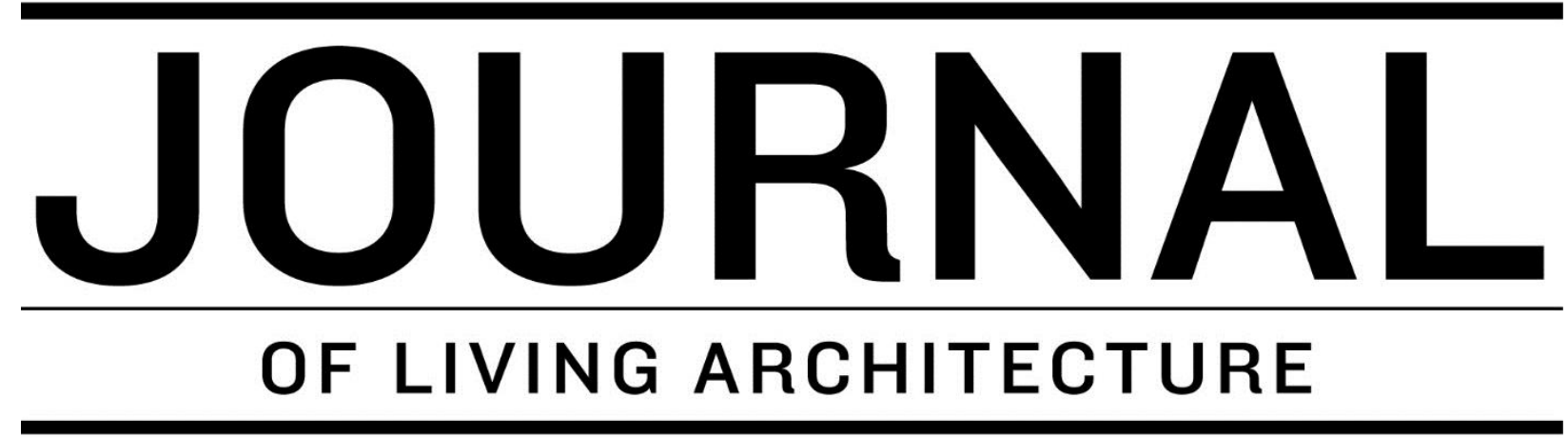

A GREEN ROOFS FOR HEALTHY CITIES PUBLICATION

Volume 3 Number 1 Pages 1-14

2016

\title{
Controlling ivy attachment to wall surfaces by applying paints, metal meshes and sheets
}

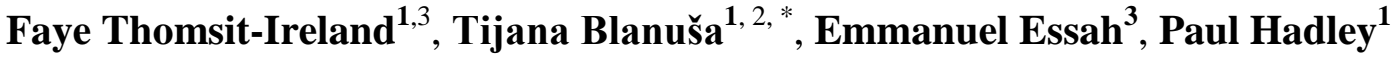 \\ ${ }^{I}$ Centre for Horticulture, School of Agriculture, Policy and Development, University of Reading, RG6 6AR, \\ United Kingdom \\ ${ }^{2}$ Plant Science Department, RHS Garden Wisley, Woking, GU23 6QB, United Kingdom \\ ${ }^{3}$ School of Construction Management and Engineering, University of Reading, RG6 6AS, United Kingdom \\ *corresponding author: tijanablanusa@rhs.org.uk
}

\begin{abstract}
Growing ivy around buildings has benefits. However, ivy potentially damages buildings which limit its use. Options for preventing ivy attachment were investigated to provide ivy management alternatives. Indoor and outdoor experiments were conducted, where metals $(\mathrm{Cu}$, $\mathrm{Zn}$ ) and anti-graffiti paints were applied to model wall panels. Metal treatments, in both indoor and outdoor experiments, fully prevented ivy attachment. For Hedera helix, silane-based antigraffiti paint prevented attachment in the laboratory and required under half the peak detachment force necessary to detach the control in the outdoor experiment. In conclusion, metals and silane-based paint are management possibilities for ivy attachment around buildings.
\end{abstract}

Key words: Hedera sp., green walls, copper, zinc, anti-graffiti paints

Please Cite as: Thomsit-Ireland, F., T. Blanuša, E. Essah and P. Hadley, 2016. Controlling ivy attachment to wall surfaces by applying paints, metal meshes and sheets. Journal of Living Architecture. 3(1): 1-14 


\section{INTRODUCTION}

The effects of green walls, plants growing around buildings, are well documented (Hunter et al. 2014, Pérez et al. 2014). Green walls can improve building insulation through the generation of stationary air (Ottelé 2011) and reduced heat loss as vegetation acts as a windbreak to protect the building (Peck et al. 1999). They can also reduce wall temperature during hot periods, due to cooling from plant evapotranspiration (Cameron et al. 2014) and shading from the foliage (Ip et al. 2004, Ip et al. 2010). Other benefits include reduced variation in wall temperature (Sternberg et al. 2011), diminished risk of freeze-thaw cycles on the exposed walls (Viles et al. 2011), and reduced wear and damage to walls by UV radiation and rain (Ashbee et al. 2010). Green walls capture particles from the air, including 10 micron particulates $\left(\mathrm{PM}_{10}\right)$ and smaller (Ottelé et al. 2010, Sternberg et al. 2011), which have been associated with increased chance of mortality and morbidity especially for those with pre-existing respiratory and cardiac complaints (Dockery and Pope 1994, Pekkanen et al. 2002, Timonen et al. 2005).

A number of vertical greening systems and solutions are currently in use for buildings' greening (Perini, Ottelé, Haas, et al. 2011). These include living walls, which are intensive systems with containers, substrate and irrigation, and green façades which are extensive systems, where plants grow in the ground or in containers and attach to the building directly or via trellises / wire / meshes. This study will focus on direct or traditional greening, a form of green façades, which employs climbing plants with suckers, attaching aerial roots, and hooks, that attach directly to the building façade. Ivy (Hedera sp.) has long been used for vertical greening due to its low cost and vigorous growth. Hibberd (1872) described the bioprotective nature of ivy on historic buildings as "the vegetable keeper of historical records".

The presence of ivy on buildings increases indoor temperature in winter (Köhler 2008) and reduces indoor temperatures (Di and Wang 1999) in summer, primarily due to shading (Cameron et al. 2014). Ivy can intercept driving rain (Rath et al. 1989) and reduce air flow around buildings (Perini, Ottelé, Fraaij, et al. 2011). In some circumstances, however, ivy can damage walls and buildings. The external render has to have sufficient strength to support the weight of the plant (along with any rain/snow loading), otherwise the plant can pull or crack external plaster or render (Rath et al. 1989). Furthermore, down pipes and gutters are at risk of detachment and blockage from plants (Rath et al. 1989). Ivy can also root into weakened historic walls or buildings that have not been maintained and can lift blocks of stone from walls by growing under them (Ashbee et al. 2010, Viles et al. 2011). Nevertheless, where the plaster was intact Rath et al. (1989) found that no damage occurred to the buildings and Viles et al. (2011) found ivy only exploited pre-existing defects in walls.

While ivy is used extensively in Europe (Köhler 2008), if introduced to an area, ivy can be a highly prolific, invasive alien (Metcalfe 2005). Although ivy has become naturalized in the United States of America, its spread and proliferation have led to "ivy deserts" in some forests (Westbrooks 1998). In the state of Oregon both Hedera helix L. and H. hibernica (G. Kirchner) Bean and all their cultivars are considered quarantinable noxious weeds which, if kept in a garden, must be prevented from spreading or seeding (Albert 2010).

From 1597 it was observed that ivy attaches to surfaces using aerial roots (Gerard 1597) (also known as clinging, holdfast, or attachment roots) which are adapted adventitious 
roots that allow ivy to self-support and climb up surfaces (Melzer et al. 2012). A number of studies have investigated the attachment of aerial roots in H. helix (Zhang et al. 2008, Melzer et al. 2009). In ivy, attachment is initially triggered by contact between the root tip and another surface (Melzer et al. 2010), which increases the number of aerial roots as well as their growth rate. The aerial roots connect with the substrate to which they are adhering, then grow to varying lengths and widths to maximize contact with the substrate (Melzer et al. 2009). As they connect with the substrate, adhesive is secreted from the aerial roots, forming droplets on the ends of the root hairs and begins to dry on contact with the substrate (Melzer et al. 2009). Analysis of secretions from ivy aerial roots revealed the adhesive is composed of uniform nanoparticles, approximately $70 \mathrm{~nm}$ in size (Zhang et al. 2008).

The force required to detach ivy was measured and it was found that ivy detachment occurs for a number of reasons: 'substrate failure' (the substrate breaks but the ivy attachment remains intact), 'root failure' (the roots break away from the substrate) or 'stem failure' (the stem breaks but the roots and substrate remain attached and intact) (Melzer et al. 2012). The substrate that the ivy adhered to, e.g. mortar, wood or tree bark, also contributed to the detachment type that occurred (Melzer et al. 2012). In another study, an adhesive from Hedera helix failed to attach to metals (aluminum and steel), PVC, Plexiglas, glass or ceramics (Melzer et al. 2009). These two studies show that attachment force can be measured and provide guidance towards materials that prevent ivy attachment.

Both $H$. helix and $H$. hibernica have been shown to climb a number of surfaces. $H$. hibernica is often used as ground cover (Rose, 1980) as it only occasionally climbs walls and seldom trees (McAllister and Rutherford 1990). However, some ivy cultivars barely climb and are bushy or erect instead (Rose 1996). While the attachment strength of $H$. helix has been studied in the past (Melzer et al. 2012), the difference in climbing tendencies of H. hibernica indicate there may be a difference in attachment adhesive and strength between species and cultivars of ivy.

This study's aim was to investigate options to control the attachment of ivy aerial roots when grown as a vertical wall cover; suitable control methods could protect fixtures and fittings, such as windows and gutters. We hypothesized that phytotoxic substances for 'true' roots were likely to also affect ivies' aerial roots; as aerial roots are a form of 'true' root and can transform into 'true' roots on contact with soil (Melzer et al. 2012). Some studies have investigated the application of chemicals to the inside of plant containers to reduce growth in 'true' / terrestrial roots through chemical root pruning. The chemicals used included emulsions of copper hydroxide, $\mathrm{Cu}(\mathrm{OH})_{2}$ (Beeson $\mathrm{Jr}$ and Newton 1992, Arnold and Struve 1993), and/or copper carbonate, $\mathrm{CuCO}_{3}$ (Struve and Rhodus 1990, Arnold and Young 1991) and the mixed metal salt of zinc carbonate and hydroxide (Baker et al. 1995). While root pruning methods were a starting point for developing aerial root detachment substances, this may present a problem with licensing in the UK. A commercial product, SpinOut ${ }^{\circledR}$, created from $\mathrm{Cu}(\mathrm{OH})_{2}$, is currently not licensed for use in the UK, so emulsions of metal salts were not considered within these experiments.

In another study, copper mesh barriers, with $1.6 \mathrm{~mm}$ openings, were tested against pruned regenerating cottonwood and birch roots (Wagar and Barker 1993). Although some of the roots protruded they were restricted to the width of the opening (Wagar and Barker 1993). 
Although copper treatments were developed for 'true' roots, the techniques and materials may be transferrable to aerial roots. There is also anecdotal evidence that ivy aerial roots do not attach to galvanized fences or galvanized sheets. Solid metal sheets or meshes could be integrated into building design or attached to building walls, so both zinc sheets and copper meshes/sheets were chosen and tested in indoor and outdoor experiments.

Although there have been no studies into the interaction between anti-graffiti paints and the attachment of self-clinging climbers, the paints are likely to have suitable properties. These include hydrophobicity and oleophobicity, thus reducing the amount of available water and potentially preventing attachment. The bonding properties of the ivy adhesive were considered important when deciding which paints to test. Two types of anti-graffiti paint were chosen for experimentation, both with the ability to repel water and oil based materials. One of the paints contained non-functional alkylsilanes (silica nanoparticles) which are both hydrophobic and lipophobic (Arkles et al. 2009). The other was a commonly used anti-graffiti paint which contained polyurethane, a petrochemical derivative. The silane-based paint may reduce attachment as it is interacting at the same spatial scale as the ivy adhesive.

Two experiments were developed to test the hypothesis that materials would prevent or reduce ivy attachment: a laboratory system with ivy cuttings and an outdoor experiment with established ivy, both with ivy growing next to cork treated with metals and paints.

\section{MATERIAL AND METHODS}

\section{Laboratory experiment}

Two year old Hedera helix (supplied by MacPennys Nurseries, Dorset, UK) and $H$. hibernica (supplied by Fibrex Nurseries Ltd, Pebworth, UK) plants were used as source material. Sixty juvenile shoot tips per species, each $15 \mathrm{~cm}$ long, were excised and subsequently maintained in $15 \mathrm{ml}$ vials containing demineralized water; experiment lasted 10 weeks ( $1^{\text {st }}$ May to $10^{\text {th }}$ July 2014$)$.

Excised shoots were grown in close proximity to $10 \mathrm{~cm}$ x $10 \mathrm{~cm}$ cork panels (Boulder Developments Ltd, Norwell, UK) treated with the following:

a. Two coats of an anti-graffiti paint 'Easy-On': a silane-based, nanoparticle paint (Urban Hygiene Ltd, South Yorkshire, UK);

b. Two coats of an anti-graffiti paint 'Pegagraff® hydro': a, petrochemical-based paint (Mathys Corporate, supplied by Graffiti Magic, Kent, UK);

c. Copper sheet, thickness $0.7 \mathrm{~mm}$ (Cooksongold, Birmingham, UK) attached to cork with adhesive (UHU All-purpose adhesive, UHU GmbH \& Co. KG, Bühl, Germany);

d. Zinc sheet, thickness $0.4 \mathrm{~mm}$ (Fab Flash Self-Adhesive Soft Zinc Alloy Flashing, Roofing Superstore, Devon, UK) attached to cork as above;

e. Control (bare, untreated cork).

Figure 1 shows the arrangement of the shoots and treatments in the experiment. Treatments were applied to cork sections, and then those sections were mounted onto $30 \times 30$ $\mathrm{cm}$ plywood panels. This was done one week before the start of the experiment, to allow any solvents from the paints and adhesives to evaporate. 
In this experiment, a replicate was two stems of an ivy species (H. helix or $H$. hibernica) in individual vials, attaching to one test material. There were six replicates (averaged from twelve pseudo-replicates) per species for each of the five treatments and 10 blocks (the 10 model panels). Vials and treatments were set-up in a balanced incomplete block design, and carried out in a laboratory environment. The average daytime light levels during the experiment were $400 \mu \mathrm{mol} \mathrm{m} \mathrm{sec}^{-1}$ whilst the average temperature was $17{ }^{\circ} \mathrm{C}$ and the average $\mathrm{RH}$ was $59 \%$. To encourage a thigmotrophic response and the production of aerial roots, the cuttings were supported with drawing pins and insulating tape as appropriate.

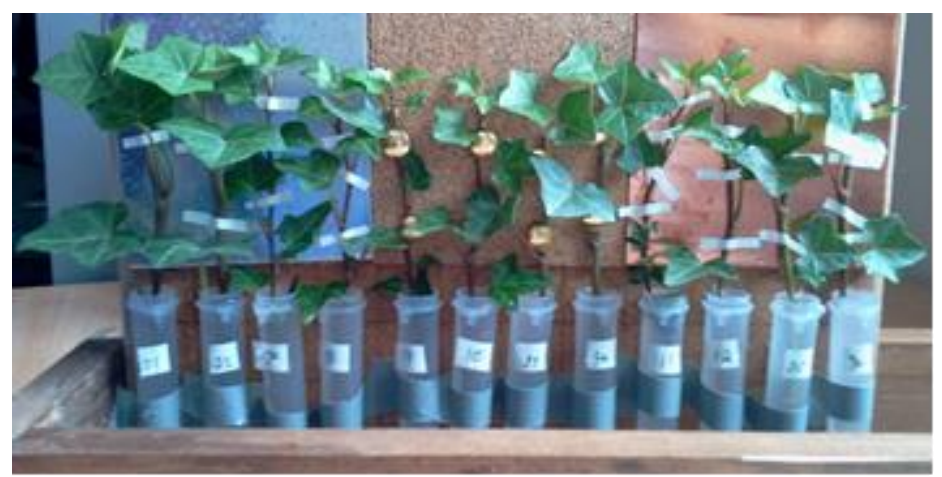

Figure 1 Ivy cuttings in a laboratory experimental set up (L to R: zinc sheet, control, copper sheet).

\section{Experimental measurements}

Initial measurements were made, on all cuttings, on $1^{\text {st }}$ May 2014 including average stem diameter (two measurements made in the center of the stem with electronic digital calipers), fresh stem weight, leaf number, and aerial root number. Subsequently, the number of aerial root attachment sites and number of leaves per cutting were recorded every two weeks; it was important not to disturb the cuttings as they were attaching, as the bonds with unfavorable surfaces could be very weak.

Final measurements were made on $10^{\text {th }}$ July 2014 and included stem length, stem weight, leaf number, total attachment length, leaf surface area (using WD3 WinDIAS leaf area meter system, Delta-T Devices Ltd., Cambridge, UK), aerial root weight and maximum vertical force required to detach cutting (using FH50 digital force gauge, Sauter GmbH Balingen, Germany). To measure the maximum vertical detachment force, the panel with the attached ivy was laid horizontally. The force gauge was hooked, using a small piece of wire, under the ivy stem between two aerial root attachment points. The wire was attached to the gauge and the gauge was lifted vertically until the ivy shoot detached from the cork section.

\section{Outdoor experiment}

A large brick building on the University of Reading Whiteknights campus was used for the experiment. Hedera helix 'Glacier' plants, established since 2008, grow next to the building façade. The ivy plants are pruned from the building façade yearly in September. At the start of the experiment, three panels were constructed from $140 \times 35 \mathrm{~cm}$ plywood with six $24 \times 30 \mathrm{~cm}$ treated cork sections mounted on each panel (Figure 2). The panels were attached to the building walls at the yearly pruning height. The experiment lasted 16 weeks $\left(26^{\text {th }}\right.$ May $-15^{\text {th }}$ September 2014). 
There were three treatments (Figure 2):

a. Two coats of an anti-graffiti paint 'Easy-On' (Urban Hygiene Ltd, South Yorkshire, UK) on a cork base;

b. Copper mesh \#60, 0.263mm Aperture - 0.16mm Wire Diameter (The Mesh Company Ltd., Warrington, UK) attached to cork with drawing pins;

c. Control (bare, untreated cork, Boulder Developments Ltd, Norwell, UK).

The painted cork sections were prepared as for the laboratory experiment. A replicate in this experiment was a test cork section, either untreated, painted with 'Easy-On' or with copper mesh attached. There were two treatment replicates per panel (Figure 2). The ivy was allowed to climb the panels naturally, resulting in between nine and twenty shoots covering each panel. The measurements on each shoot on the panel were averaged to give a mean measurement for each panel which was then subjected to the statistical analysis. There were therefore, three treatments with six replicates per treatment and three blocks (for the three panels).

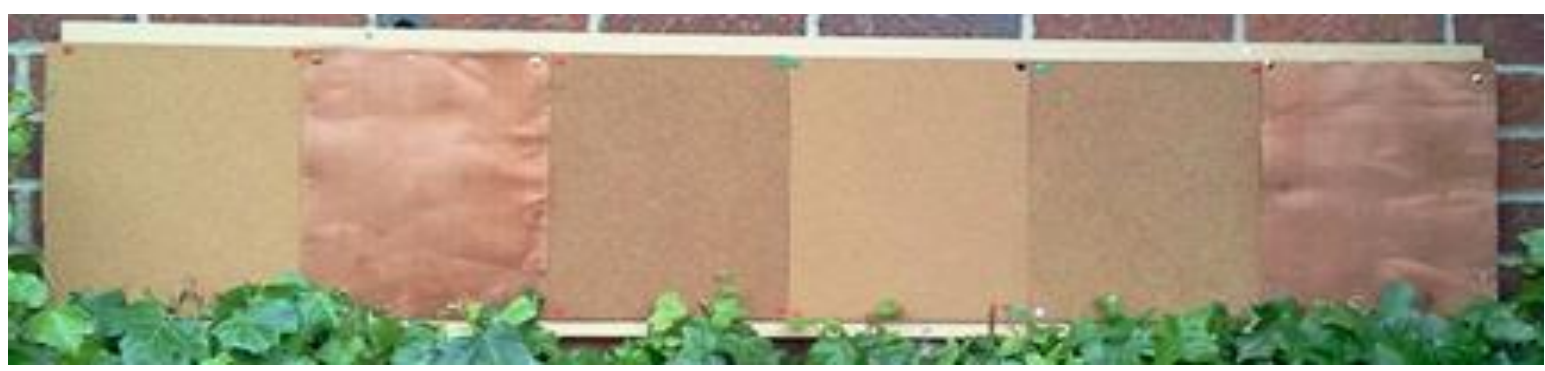

Figure 2 One of the model outdoor walls at the start of the outdoor experiment; it shows two replicates of the treatments ( $\mathrm{L}$ to $\mathrm{R}$ : control, copper mesh, anti-graffiti paint 'Easy on', control, antigraffiti paint 'Easy on' and copper mesh).

\section{Experimental measurements}

At the end of the experiment, $15^{\text {th }}$ September 2014, shoots were removed from the panels. For each attached shoot, the maximum detachment force, whether the stem broke, shoot length from the bottom of the cork panel, stem diameter (two measurements made in the center of the stem), aerial root attachment length, leaf area, and dry biomass (total biomass, i.e. stem, leaves and aerial roots; aerial roots; and leaves) were measured. The detachment force was measured in the same was as for the laboratory experiments.

\section{Statistical analyses}

Analysis of variance (ANOVA) using GenStat (16th Edition, Lawes Agricultural Trust, Rothamsted Experimental Station, UK) was used to assess the effects of species (in the laboratory experiment), and different coatings (in both experiments) on measured parameters. Variances were checked for homogeneity and values were presented as means with associated standard error of the mean (S.E.M.) and least significant differences (L.S.D.) when the ANOVA showed a significant difference. In the outdoor experiment, to avoid pseudoreplication, the mean parameter values per panel were calculated from the individual stem values.

When assessing the stem breaks, the breakages were fitted to a binomial distribution, where a stem break was assigned a value of one and no stem break was assigned a zero value. 
In both the laboratory and outdoor experiments there were a high number of zero values in the detachment force terms, so the analysis was broken into two sections. The likelihood of attachment was described as an odds ratio between the treatments, i.e. attachment was given the value 1 and no attachment was 0 . Then a logistic regression, with a binomial distribution using the logit transformation, was performed.

To identify whether there was a significant difference between the treatments, when attachment occurred an ad hoc ANOVA test was performed on the data set with zero values excluded. To prevent low statistical power and an increased probability of a Type II error (false acceptance of the null hypothesis), only treatments with at least three non-zero values were considered.

\section{RESULTS}

\section{Laboratory Experiment}

Cuttings' growth parameters

There were significant differences in the initial stem diameter, stem weight, leaf number and aerial root number between the two species, so $H$. helix and H. hibernica were analyzed separately. For each species there were no significant differences between the treatments in the initial parameters measured: average stem diameter, stem weight, leaf number and aerial root number (data not shown), suggesting that the treatments did not affect the growth of cuttings. The average initial stem diameter across treatments for H. helix was $1.57 \mathrm{~mm} \approx 39 \%$ smaller than $H$. hibernica $2.47 \mathrm{~mm}$, and there were initially $50 \%$ more leaves and three times more aerial roots in H. helix than H. hibernica (3.2 and 2.1 leaves per cutting, 28 and 9 aerial roots per cutting, respectively).

During the experiment $H$. helix cuttings elongated more: $38 \mathrm{~mm}$ versus $27 \mathrm{~mm}$ for $H$. hibernica, but gained $32 \%$ less weight than $H$. hibernica $0.34 \mathrm{~g}$ and $0.50 \mathrm{~g}$ respectively (data not shown). There was no significant growth difference between treatments for either species and the final average leaf area per cutting of $H$. helix was $29 \%$ less than $H$. hibernica $17 \mathrm{~cm}^{2}$ and $24 \mathrm{~cm}^{2}$ respectively (data not shown).

\section{Attachment of cuttings to wall surfaces}

The number of attachment sites, assessed at the end of the experiment, was similar between species and there was no significant difference between the treatments (Table 1). However, in $H$. hibernica the final average aerial root weight per cutting for the control was significantly lower than both copper and 'Easy on' (i.e. $0.012 \mathrm{~g}$ compared to $0.028 \mathrm{~g}$ and $0.026 \mathrm{~g}$, respectively; $\mathrm{P}=0.028$ ).

Both the force per attachment length and peak detachment force have been measured (Table 1). The force per attachment length was useful where two species were being compared, as one species could have a weak force per attachment length, but a greater attachment length than the other. For example, two shoots could have the same peak detachment force e.g. $20 \mathrm{~N}$, but different attachment lengths, e.g. $1 \mathrm{~cm}$ versus $2 \mathrm{~cm}$ and for the greater attachment length, the force per centimeter would only be $10 \mathrm{~N}$. For industry, peak force is probably more useful as it displays the force required to remove the attached ivy from the surface (Table 1). 
Table 1 Detachment parameters at the end of the 10 week experiment, for Hedera helix and $H$. hibernica: aerial root weight $(\mathrm{g})$, detachment force per attachment length $\left(\mathrm{N} \mathrm{mm}^{-1}\right)$, length of attachment $(\mathrm{mm})$ and peak detachment force $(\mathrm{N})$. Where there was no attachment and therefore no force required to detach the cuttings, the 0 values were excluded from ANOVA, hence different degrees of freedom, blocking 'wall' factor removed for detachment force and length of attachment, for both species as it was not significant and sample size too small. Data are means of six replicates per treatment with SEM $(\mathrm{n}=6$, treatments $=5$, blocks $=10)$.

\begin{tabular}{|c|c|c|c|c|c|c|c|c|}
\hline \multirow[t]{2}{*}{$\begin{array}{l}\text { Species/ } \\
\text { Treatment }\end{array}$} & \multicolumn{2}{|c|}{$\begin{array}{l}\text { Aerial root weight } \\
(\mathrm{g})\end{array}$} & \multicolumn{2}{|c|}{$\begin{array}{l}\text { Detachment force per } \\
\text { length of attachment } \\
\left.(\mathrm{N} \mathrm{mm})^{-1}\right)\end{array}$} & \multicolumn{2}{|c|}{$\begin{array}{l}\text { Length of attachment } \\
(\mathrm{mm})\end{array}$} & \multicolumn{2}{|c|}{$\begin{array}{l}\text { Peak detachment } \\
\text { force }(\mathrm{N})\end{array}$} \\
\hline & H. helix & $\begin{array}{l}H . \\
\text { hibernica }\end{array}$ & H. helix & $\begin{array}{l}H . \\
\text { hibernica }\end{array}$ & H. helix & $\begin{array}{l}H . \\
\text { hibernica }\end{array}$ & H. helix & $\begin{array}{l}\text { H. } \\
\text { hibernica }\end{array}$ \\
\hline Control & 0.009 & 0.012 & 0.18 & 0.16 & 23 & 20 & 4.0 & 3.1 \\
\hline 'Easy on' & 0.013 & 0.026 & - & 0.01 & - & 12 & - & 0.4 \\
\hline 'Pegagraff' & 0.008 & 0.015 & 0.09 & 0.12 & 18 & 23 & 1.7 & 2.7 \\
\hline Copper & 0.013 & 0.028 & - & - & - & - & - & \\
\hline Zinc & 0.012 & 0.020 & - & - & - & - & - & \\
\hline $\mathrm{P}$ value & $\begin{array}{l}0.533 \\
(\text { d.f. }=16)\end{array}$ & $\begin{array}{l}0.028 \\
(\text { d.f. }=16)\end{array}$ & $\begin{array}{l}<0.001 \\
(\text { d.f. }=10)\end{array}$ & $\begin{array}{l}0.007 \\
(\text { d.f. }=6)\end{array}$ & $\begin{array}{l}0.318 \\
(\text { d.f. }=10)\end{array}$ & $\begin{array}{l}0.036 \\
(\text { d.f. }=12)\end{array}$ & $\begin{array}{l}0.009 \\
(\text { d.f. }=10)\end{array}$ & $\begin{array}{l}<0.001 \\
(\text { d.f. }=12)\end{array}$ \\
\hline SEM & 0.002 & 0.004 & 0.01 & 0.02 & 3 & 2 & 0.5 & 0.4 \\
\hline L.S.D & & 0.011 & 0.04 & 0.05 & & 8 & 1.6 & 1.3 \\
\hline
\end{tabular}

Although there were differences in the number of leaves, leaf surface area and stem weight between the species, their attachment response to different treatments was broadly similar (Table 1). Neither H. helix nor H. hibernica attached to either of the metals (Table 1). $H$. helix did not form an attachment to 'Easy on' whereas $H$. hibernica formed a weak bond. Both species attached to 'Pegagraff' and the detachment force per length of attachment was significantly less than the control for $H$. helix $\left(0.09\right.$ versus $0.18 \mathrm{~N} \mathrm{~mm}^{-1}, \mathrm{P}<0.001$, LSD = 0.04). However there was no significant difference between the control and 'Pegagraff' for $H$. hibernica. For both species, the attachment length for the control and 'Pegagraff' treatments were not significantly different (Table 1). In H. hibernica the attachment length of 'Easy on' treatment was $40 \%$ less than the control $(\mathrm{P}=0.036)$. There was no significant difference in the detachment force required to remove $H$. helix and $H$. hibernica for the same treatment (apart from for 'Easy on' where H. hibernica formed a bond and H. helix did not). In H. helix there was significantly less detachment force required to remove the stems that attached to the 'Pegagraff' treatment compared to the control $(1.7 \mathrm{~N}$ and $4.0 \mathrm{~N}$ respectively, $\mathrm{P}=0.009)$. However, in H. hibernica the detachment force was similar between the 'Pegagraff' treatment and the control.

\section{Outdoor experiment}

\section{Growth of ivy plants against wall treatments}

There was no significant difference in the measured growth parameters (i.e. dry stem biomass, stem length and diameter) between the treatments, suggesting that the treatments did not affect the growth of the ivy shoots (data not shown). 


\section{Attachment of ivy to wall treatments}

There was no difference between treatments in aerial root biomass (Table 2). As these values represent the average root biomass per panel, the percentage of individual stem attachments has been included to highlight that the average values for 'Easy on' include 30\% zero values where the stems did not attach. There was a significant, seven-fold increase in number of stem breaks in the control treatment versus 'Easy on' (Table 2). Thus $49 \%$ of the time the maximum detachment force for the control was greater than the strength of the ivy stem; however that only occurred in 7\% of the cases for 'Easy on'. Both the peak detachment force and the detachment force per length of attachment showed that significantly more force was required to detach the stems from the control than from 'Easy on'. The shoots on copper formed no attachment (Table 2).

Table 2 Detachment parameters: mean dry aerial root biomass, percentage of attached stems, stem break distribution, peak detachment force, and detachment force per length of attachment. H. helix 'Glacier' shoots grew next to cork sections with three treatments: control/ untreated cork, copper mesh, and a silane based anti-graffiti paint 'Easy on'. Data are means of between 9 and 20 shoots per panel. If there was a significant difference the LSD is shown. As no stems attached to copper there are no values for detachment or stem break, and those zero values were excluded from the ANOVA, hence the different degrees of freedom shown $(n=6$, treatments $=3$ and blocks $=3)$.

\begin{tabular}{llllll}
\hline & $\begin{array}{l}\text { Dry aerial root } \\
\text { biomass }(\mathrm{g})\end{array}$ & $\begin{array}{l}\text { Percentage of } \\
\text { attached stems } \\
(\%)\end{array}$ & $\begin{array}{l}\text { Stem } \\
\text { break } \\
(\mathrm{Y} / \mathrm{N})\end{array}$ & $\begin{array}{l}\text { Peak } \\
\text { detachment } \\
\text { force }(\mathrm{N})\end{array}$ & $\begin{array}{l}\text { Detachment force per } \\
\text { attachment length } \\
\left(\mathrm{N} \mathrm{mm}^{-1}\right)\end{array}$ \\
\hline Control & 0.07 & 100 & 0.49 & 23 & 0.20 \\
'Easy on' & 0.12 & 70 & 0.07 & 10 & 0.05 \\
Copper & 0.08 & 0 & - & - & - \\
P value & 0.06 & & $<0.001$ & 0.001 & 0.002 \\
d.f. & 13 & & 8 & 8 & 8 \\
\hline SEM & 0.02 & & 0.05 & 2 & 0.02 \\
\hline LSD & & & 0.15 & 6.12 & 0.08 \\
\hline
\end{tabular}

\section{DISCUSSION}

Results from the laboratory experiment show that Hedera helix had thinner stems, with more, smaller-sized leaves, which weighed less than the stems and leaves of $H$. hibernica. However, $H$. helix produced significantly more aerial roots per stem and attached to surfaces easier than $H$. hibernica. The wall treatments did not significantly influence the measured growth parameters of the cuttings in either species. While this experiment indicated that $H$. hibernica was the slower growing species, in field experiments performed by McAllister and Rutherford (1990) H. hibernica was found to be a faster-growing and more vigorous plant. This suggests that the cuttings may behave differently to the whole plant. Some of our other findings such as the smaller leaves (in H. helix) and thicker stems (in $H$. hibernica) have been described before (McAllister and Rutherford 1990).

Both species responded comparably to the wall treatments. Zinc and copper prevented attachment, and 'Easy on' prevented attachment from H. helix and partially prevented attachment of $H$. hibernica. Both species formed a bond with 'Pegagraff' however, in $H$. 
helix the bond was significantly less than the control, and for H. hibernica the bond strength was similar to the control. This may indicate a difference in the adhesive composition between species. 'Easy on' produced the greatest reduction in attachment of the anti-graffiti paints tested. Melzer et al. (2009) suggested that aerial roots in H. helix were unable to attach to aluminum or steel due to the minimal pore size of metals or an unreactive surface preventing adhesive bonding. In our experiment, it may be due to the phytotoxicity of zinc and copper. To elucidate the exact cause of the adhesion or prevention thereof, further studies would be required. The technical data suggest that many industrial tests have been performed on 'Easy on' but some clarification as to water permeability and building "breathability" would be useful before extensive use of this product to aid ivy management around walls.

The aerial roots' weight at the end of the experiment was significantly greater for the copper and 'Easy on' treatments than the control in H. hibernica (Table 1). This was probably because the aerial roots that adhered to the treated cork dried out and were frequently left attached to the cork due to the strength of their adhesive. Therefore the aerial root weight in the unattached treatments indicate that the cuttings were growing healthily and producing large numbers of aerial roots even when the cuttings did not attach.

There was only a significant difference in the peak attachment strength between the two species for the 'Easy on' treatment as H. hibernica formed a bond where H. helix did not. This may indicate a difference in adhesive composition between $H$. helix and $H$. hibernica which could warrant additional investigation. Neither species attached to the metals, indicating the metals are a reliable choice to prevent attachment; however, their cost (data not shown) may deter use.

In the outdoor experiment, the treatments did not significantly influence the measured growth parameters of the shoots growing over them, indicating that the plants were not affected by the treatments. The main differences between treatments came from the extent of the attachment. This supported the results of the laboratory experiment and, additionally showed that 60\# copper mesh prevented aerial root attachment. While 'Easy on' still showed a significant decrease in root attachment compared to the control, it was not as effective as copper in situ, indicating that the anti-graffiti paint 'Easy on' may need some form of additional treatment/control in order to achieve full detachment.

In our experiment, the treatments prevented attachment over the treated area, but the ivy was then able to attach to the wall above the treated area. This indicates that further work is required to prevent ivy attaching higher up and continuing to cause complications.

\section{CONCLUSIONS}

Under laboratory and outdoor conditions, zinc and copper sheets, copper mesh and silane-based anti-graffiti paint all prevented or severely weakened ivy attachment to cork. The ivy strongly attached to the cork when it was not treated. While cork is not a true replica of a brick and mortar wall, these treatments may be used on buildings. It is important to reduce the gap between metal sheeting and wall, as ivy will climb under the mesh or behind the sheet if there is an opportunity. The silane-based paint would not have that problem, but it does not fully stop attachment. Cork is a comparatively smooth surface, and with the additional grooves in bricks, the protection provided by the silane-based paint may not be enough to 
prevent attachment. This work highlights some options for ivy control and management on buildings, providing methods to reduce the opportunity for ivy to creep into gutters or windows. From a cost comparison (data not shown), the silane-based anti-graffiti paint was the cheapest solution. From the information provided by 'Easy-On' the anti-graffiti paint provides up to 22 years of protection from graffiti (Urban Hygiene Ltd. 2010). Aerial roots are however different, as if they do attach, they will leave residue which may make it easier for the next layer to attach. Therefore, this coating should be considered as a deterrent from which the ivy shoots can be brushed from the wall, rather than a full inhibitor, repeated attachment and repainting, may be investigated in the future. In conclusion, copper and zinc could be used to manage ivy around vulnerable areas. However, as 'Easy on' is a clear paint it would be the most discrete deterrent, with the least visual impact. Providing it did not adversely affect the building, such as trapping moisture in the masonry, this would be the treatment to be investigated further.

\section{ACKNOWLEDGEMENTS}

This work was financially supported by the Royal Horticultural Society (RHS), Sutton Griffin Architects, and Engineering and Physical Sciences Research Council (ESPRC) grant EP/G037787/1 to the Technologies for Sustainable Built Environments Centre (TSBE) at University of Reading. The authors thank Roderick Griffin, Chris Trickey, Val Jasper, Tobias Lane and Matthew Richardson for their expert technical help.

\section{LITERATURE CITED}

Albert, L. 2013. Under Quarantine: Ivy, Butterfly Bush, Scotch Broom and Their Cultivars Face Tough New State Rules. The Oregonian 2010 [cited 23/03/2013 2013]. Available from http://www.oregonlive.com/hg/index.ssf/2010/03/under_quarantine_ivy_butterfly.html.

Arkles, B., Pan, Y., and Kim, Y. M. 2009. "The Role of Polarity in the Structure of Silanes Employed in Surface Modification." Silanes and other coupling agents no. 5:51.

Arnold, M. A., and Struve, D. K. 1993. "Root distribution and mineral uptake of coarse-rooted trees grown in cupric hydroxide-treated containers." HortScience no. 28:988-992.

Arnold, M. A., and Young, E. 1991. "CuCO3-painted containers and root pruning affect apple and green ash root growth and cytokinin levels." HortScience no. 26:242-244.

Ashbee, J., Cathersides, A., Sternberg, T., Thomas, R., Turner, C., Viles, H., and White, A. 2010. "Ivy on Walls: Seminar Report." English Heritage

Baker, J. F., Burrows, N. L., Keohane, A. E., and de Filippis, L. F. 1995. "Chemical root pruning of kangaroo paw (Anigozanthos flavidus) by selected heavy metal carbonates." Scientia Horticulturae no. 62 (4):245-253.

Beeson Jr, R. C., and Newton, R. 1992. "Shoot and Root Responses of Eighteen Southeastern Woody Landscape Species Grown in Cupric Hydroxide-treated Containers." Environ Hortic no. 10:214-217. 
Cameron, R. W. F., Taylor, J. E., and Emmett, M. R. 2014. "What's 'cool' in the world of green façades? How plant choice influences the cooling properties of green walls." Building and Environment no. 73:198-207.

Di, H. F., and Wang, D. N. 1999. "Cooling Effect of Ivy on a Wall." Experimental Heat Transfer: A Journal of Thermal Energy Generation, Transport, Storage, and Conversion no. 12 (3):235245 .

Dockery, D. W., and Pope, C. A. 1994. "Acute Respiratory Effects of Particulate Air Pollution." Annual Review of Public Health no. 15:107-132.

Gerard, J. 1597. The Herball Or Generall Historie of Plantes: Norton, John.

Hibberd, J. S. 1872. The ivy, a monograph. London: Groombridge \& sons.

Hunter, A. M., Williams, N. S. G., Rayner, J. P., Aye, L., Hes, D., and Livesley, S. J. 2014. "Quantifying the thermal performance of green façades: A critical review." Ecological Engineering no. 63:102-113.

Ip, K., Lam, M., and Miller, A. 2010. "Shading performance of a vertical deciduous climbing plant canopy." Building and Environment no. 45:81-88.

Ip, K., Marta, L., and Miller, A. 2004. "Bioshaders for sustainable buildings."

Köhler, M. 2008. "Green facades—a view back and some visions." Urban Ecosystems no. 11:423436.

McAllister, H. A., and Rutherford, A. 1990. "Hedera helix L. and H. hibernica (Kirchner) Bean (Araliaceae) in the British Isles." Watsonia no. 18:7-15.

Melzer, B., Seidel, R., Steinbrecher, T., and Speck, T. 2012. "Structure, Attachment Properties, and Ecological Importance of the Attachment System of English Ivy (Hedera helix)." Journal of experimental botany no. 63 (1):191-201.

Melzer, B., Steinbrecher, T., Seidel, R., Kraft, O., Schwaiger, R., and Speck, T. 2010. "The Attachment Strategy of English Ivy: A Complex Mechanism Acting on Several Hierarchical Levels." Journal of the Royal Society Interface no. 7 (50):1383-9.

Melzer, B., Steinbrecher, T., Seidel, R., Kraft, O., and Speck, T. 2009. Mechanics and Structure of the Attachment System of English Ivy ( Hedera helix L .). Paper read at 6th Plant Biomechanics Conference at Cayenne.

Metcalfe, D. J. 2005. "Hedera helix L." Journal of Ecology no. 93:632-648.

Ottelé, M. 2011. The Green Building Envelope Vertical Greening, Technische Universiteit Delft

Ottelé, M., van Bohemen, H. D., and Fraaij, A. L. A. 2010. "Quantifying the deposition of particulate matter on climber vegetation on living walls." Ecological Engineering no. 36:154-162. 
Peck, S. W., Callaghan, C., Kuhn, M. E., and Bass, B. 1999. "Greenbacks From Green Roofs :

Forging A New Industry In Canada: Status Report on Benefits, Barriers and Opportunities for Green Roof and Vertical Garden Technology Diffusion " [Ottawa]: Canada Mortgage and Housing Corporation

Pekkanen, J., Peters, A., Hoek, G., Tiittanen, P., Brunekreef, B., de Hartog, J., Heinrich, J., IbaldMulli, A., Kreyling, W. G., Lanki, T., Timonen, K. L., and Vanninen, E. 2002. "Particulate Air Pollution and Risk of ST-Segment Depression During Repeated Submaximal Exercise Tests Among Subjects With Coronary Heart Disease: The Exposure and Risk Assessment for Fine and Ultrafine Particles in Ambient Air (ULTRA) Study." Circulation no. 106 (8):933938.

Pérez, G., Coma, J., Martorell, I., and Cabeza, L. F. 2014. "Vertical Greenery Systems (VGS) for energy saving in buildings: A review." Renewable and Sustainable Energy Reviews no. 39:139-165.

Perini, K., Ottelé, M., Fraaij, A. L. A., Haas, E. M., and Raiteri, R. 2011. "Vertical greening systems and the effect on air flow and temperature on the building envelope." Building and Environment no. 46:2287-2294.

Perini, K., Ottelé, M., Haas, E. M., and Raiteri, R. 2011. "Greening the building envelope, façade greening and living wall systems." Open Journal of Ecology no. 01 (01):1-8.

Rath, J., Kieß1, K., and Gertis, K. 1989. Auswirkungen von Fassadenbegrünungen auf den Wärmeund Feuchtehaushalt von Außenwänden und Schadensrisiko: Fraunhofer IRB-Verlag: IBPBericht FtB - 4/1989.

Rose, P. Q. 1996. The Gardener's Guide to Growing Ivies: Timber Press, Incorporated.

Sternberg, T., Viles, H., and Cathersides, A. 2011. "Evaluating the Role of Ivy (Hedera Helix) in Moderating Wall Surface Microclimates and Contributing to the Bioprotection of Historic Buildings." Building and Environment no. 46 (2):293-297.

Struve, D. K., and Rhodus, T. 1990. "Turning copper into gold." American Nurseryman no. 172:114125 .

Timonen, K. L., Vanninen, E., de Hartog, J., Ibald-Mulli, A., Brunekreef, B., Gold, D. R., Heinrich, J., Hoek, G., Lanki, T., Peters, A., Tarkiainen, T., Tiittanen, P., Kreyling, W., and Pekkanen, J. 2005. "Effects of ultrafine and fine particulate and gaseous air pollution on cardiac autonomic control in subjects with coronary artery disease: The ULTRA study." J Expos Sci Environ Epidemiol no. 16 (4):332-341.

Urban Hygiene Ltd. 2010. easy-on ${ }^{\mathrm{TM}}$ Durability coating Technical Data MSDS.

Viles, H., Sternberg, T., and Cathersides, A. 2011. "Is Ivy Good or Bad for Historic Walls?" Journal of Architectural Conservation no. 17:25-41.

Wagar, J. A., and Barker, P. A. 1993. "Effectiveness of three barrier materials for stopping regenerating roots of established trees." Journal of Arboriculture no. 19:332-332. 
Westbrooks, R. G. 1998. "Invasive plants: changing the landscape of America." US Government Documents (Utah Regional Depository):490.

Zhang, M., Liu, M., Prest, H., and Fischer, S. 2008. "Nanoparticles Secreted from Ivy Rootlets for Surface Climbing." Nano Letters no. 8 (5):1277-1280. 